\section{Projetos Socioeducativos. A naturalização da exclusão nos discursos de educadores}

\author{
Dinora Tereza Zucchetti ${ }^{1}$ \\ Eliana Perez Gonçalves de Moura ${ }^{2}$ \\ Magali Mendes de Menezes ${ }^{3}$
}

Resumo: O artigo aborda a temática da exclusão/inclusão em práticas de educação não escolar, a partir dos discursos de educadores que atuam em projetos socioeducativos voltados a crianças e jovens, moradores de periferias urbanas. Considerando-se alguns resultados das pesquisas empíricas Formação de Educadores em Práticas Socioeducativas (CNPq) e Saberes sobre Diferenças e Inclusão Social, os projetos socioeducativos são tidos como ações eminentemente inclusivas, naturalizando o fenômeno da exclusão/inclusão social. Propõe-se a ampliação dessa discussão a partir de argumentos que apontam para a ausência de um fundamento importante, a saber, a dimensão da desigualdade.

Palavras-chave: políticas públicas; exclusão/inclusão; desigualdade; projetos socioeducativos; práticas de educação.

\section{Introdução}

ste artigo busca problematizar a questão da inclusão social, desde práticas educativas em espaços não escolares, mais especificamente as que ocorrem no interior de projetos de caráter socioeducativo orientados para crianças e jovens.

Entende-se por práticas socioeducativas, segundo os estudos de Carvalho e Azevedo (2004), as ações que são complementares à escola e que conjugam educação e proteção social que, quando voltadas às crianças e jovens, acontecem no período alternado à escola e, em conjunto, investem suas atividades no desenvolvimento integral desses sujeitos. São, portanto, "ações que fazem da educação para o convívio em sociedade e para o exercício da cidadania uma estratégia de proteção à infância e a juventude" (Carvalho e Azevedo, 2004, s.p.).

Sem que as referidas autoras nomeiem essas ações como educação não esco$\operatorname{lar}^{4}$ - expressão que tem sido utilizada, comumente, como sinônimo de educação informal/não formal, entre outras, - e prefiram utilizar a expressão "ações complementares à escola", o que temos em questão são práticas educativas que ocorrem na modalidade extra escolar, externas ao sistema escolar, relacionadas
Recebimento:

03.2010

Aprovado:

09.2010

1. Doutora em Educação. Professora do Mestrado em Inclusão Social e Acessibilidade/Feevale.

dinora@feevale.br

2. Doutora em Educação. Professora do Mestrado em Inclusão Social e Acessibilidade/Feevale.

elianapgm@feevale br

3. Doutora em Filosofia. Professora do Mestrado Acadêmico em Processos e Manifestações Culturais/ Feevale.

magalimm@terra. com.br

4. Sobre a forma de nomeação "educação não escolar" existem argumentos que nos levam a assumi-la como preferencial, conforme Moura \& Zucchetti (2007, 2009) e Zucchetti \& Moura (2007). Também, consonante com esta forma de nomeação, Sérgio Haddad entende "por educação não escolar todas aquelas práticas educativas formais ou não formais desenvolvidas fora do contexto da escola e que estão voltadas principalmente para a formação política e cidadã e no atendimento de necessidades de natureza econômica, sócio ambiental e cultural" (Haddad, 2009: 162) 
à formação da cidadania e que tensionam a relação sociabilidade/educação. Essa relação também permeia a construção de metodologias de práticas socioeducativas que têm seu foco de intervenção em sujeitos que, a priori, são definidos como "seres de falta". A ausência de condições adequadas de habitação, a falta de cuidado por parte de familiares, histórias de evasão e o precário aproveitamento escolar, a presença da rua como espaço de sociabilidade, entre outros, têm sido considerados motivos pelos quais crianças e jovens passam a ser encaminhados, por professores, conselheiros tutelares e pelos próprios familiares, a projetos sociais. Estes, em geral, têm forte apelo compensatório desde onde questões acerca da temática da inclusão social têm sido ressaltadas como naturais, isto é, são consideradas como próprias de espaços que se dispõem a acolher e atender sujeitos que não têm suas necessidades básicas satisfeitas e, por isso, são inclusivos por excelência.

Problematizar a naturalização do fenômeno exclusão/inclusão, bem como os discursos sobre a ação inclusiva de projetos socioeducativos, verificando de que forma os educadores que atuam nestas práticas afinam ou não com os discursos predominantes, é o mote deste artigo. Para tanto, os dados empíricos que se apresentam à análise são os discursos de educadores oriundos das pesquisas Formação de Educadores em Práticas Socioeducativas (CNPq) e Saberes sobre Diferenças e Inclusão Social, pesquisas estas desenvolvidas por pesquisadoras de uma Instituição de Ensino Superior - IES, do Vale do Sinos/RS, entre os anos de 2005 a 2008.

As investigações, de natureza qualitativa, coletaram dados através de observação, entrevistas, aplicação de questionários e participação em reuniões de formação pedagógica. Posteriormente, as análises foram realizadas pela metodologia de Análise de Conteúdo. Segundo Bardin (1991), a Análise de Conteúdo:

(...) aparece como um conjunto de técnicas de análises de comunicações, que utiliza procedimentos sistemáticos e objetivos do conteúdo de mensagens. (...) O interesse não reside na descrição dos conteúdos, mas sim no que estes nos poderão ensinar após serem tratados relativamente a 'outras coisas'. A intenção da análise de conteúdo é a inferência de conhecimentos relativos às condições de produção e recepção das mensagens, inferência esta que recorre a indicadores (quantitativos, ou não). [Grifos do autor] (p. 38)

A Análise de Conteúdo, em consonância com Franco (2008), nos mostra que toda fala traz informações sobre o autor (filiações teóricas, concepções de mundo, etc.). Portanto, o sujeito da fala, ao expressar-se, o faz de acordo com o seu quadro de referência e, por último, a teoria na qual o autor/informante se filia (mesmo que não necessariamente reconheça essa filiação) orienta a sua con- 
cepção de realidade que, por sua vez, é orientadora dos discursos produzidos. Desse modo, essa escolha metodológica, nos possibilita perceber de que forma os discursos se sustentam e sob que concepções políticas podemos pensar essa proposta de Educação.

2. Posicionando a questão da exclusão/inclusão social nas pesquisas realizadas

Sem o objetivo de apresentar detalhadamente todos os achados das pesquisas que emprestam seus dados à análise para a produção deste artigo, nessa sessão nos atemos em identificar, através dos resultados das investigações, os discursos de educadores sobre a exclusão/inclusão social.

A primeira ${ }^{5}$ investigação analisada, intitulada Formação de Educadores em Práticas Socioeducativas (CNPq), analisou a formação pedagógica de equipes de trabalho compostas por educadores e gestores de projetos socioeducativos em duas instituições de um município do Vale dos Sinos/RS. Foram realizadas 8 (oito) reuniões de periodicidade quinzenal, em que participaram 12 (doze) sujeitos.

Essa pesquisa objetivou compreender como se constrói o educador a partir das concepções de jovem, trabalho e educação presentes na formação pedagógica e analisar como acontece a formação de educadores em serviço nas práticas de educação não escolar junto a grupos sociais em situação de vulnerabilidade. Para tanto, tomou-se como lugar do empírico uma instituição governamental cuja gestão de seus projetos recai sobre o poder público municipal e a outra não governamental, de Terceiro Setor.

A análise das transcrições das reuniões traduziu-se numa estratégia que permitiu verificar a quase inexistência de divergências entre os educadores dos dois grupos de trabalho quanto aos dilemas enfrentados na prática profissional. Esse dado nos mostrou que não era necessário, nesse caso, considerar uma variável para possíveis diferenças de intervenção pedagógica entre os educadores que atuam na instituição governamental e não governamental. Independente da escolarização dos educadores, que têm, em geral, ensino fundamental ou superior incompleto, e da existência, ou não, de inserção acadêmica na área de formação de professores, todos ressaltam que a especificidade do trabalho educativo, no campo social, demanda por formação específica ${ }^{6}$.

Quanto aos dados empíricos, foi o Relatório Final da investigação — onde estão descritas as discussões ocorridas, gravadas e transcritas, nas reuniões pedagógicas - que nos permitiu verificar a presença da questão da exclusão/inclusão na pesquisa.
5. O uso da expressão "primeira" não significa a ordem cronológica das pesquisas, mas a utilização de um recurso para a apresentação do texto.

6. Uma formação pedagógica que contemple a educação no campo social tem se apresentado como uma questão recorrente para os educadores que atuam em práticas socioeducativas, nas investigações realizadas pelas autoras. No entanto, esse tema não será objeto de reflexão teórica neste artigo. 
7. Essa citação é um excerto da versão do Projeto Agente Jovem 2004/2005 (s.p.), realizado pelo município sede da ação. A versão do referido projeto consta nos anexos do Relatório Final da Pesquisa.
No referido Relatório de 152 páginas, utilizando-se o recurso de editar/localizar do Microsoft Word, foi possível pesquisar as palavras: incluir, inclusão, incluídos, excluir, exclusão, excluídos e os sentidos que são atribuídos a elas. Como resultado, foram localizadas duas referências à inclusão, as demais expressões não foram encontradas.

Em um primeiro sentido, incluir tem conotação de acolhimento, de fazer parte, no sentido de obter uma vaga no projeto. Nesse sentido, diz a coordenadora pedagógica: "Então tu podes incluir a C., o avançado [referência à modalidade do curso de informática] abre duas vagas, se a S. S. e a E. não virem mais" (relato de reunião). No outro sentido, o termo inclusão refere-se à inclusão de jovens, destacando-se como trabalho e, ao mesmo tempo, como constitutivo de sua humanidade.

Nesta perspectiva da CENTRALIDADE DA VIDA, ninguém melhor do que o jovem para ser o protagonista de um projeto com esta intencionalidade. Já a perspectiva de qualificação formal para o trabalho, se não definida de forma direta, precisa estar presente de outras formas, pois o trabalho tem se constituído numa importante forma de inclusão social para uma parcela significativa da população, especialmente para os jovens aos quais o projeto se destina. No entanto, as questões vinculadas ao meio ambiente, associadas ao protagonismo dos atores envolvidos no projeto, poderão facilitar a compreensão de que o humano é ao mesmo tempo indivíduo, parte da sociedade e parte da espécie?

Esse excerto reforça que a experiência do trabalho aparece como um elemento inclusivo na formação de um indivíduo útil para o trabalho, atribuindo-lhe centralidade na formação de jovens, especialmente das classes populares.

No geral, os dados apresentados reforçam que a tese relativa às questões da exclusão/inclusão social dos segmentos com os quais atuam os educadores pesquisados é quase inexistente e pouco problematizada.

Assim, nossa análise sobre o material nos permite identificar a ausência de uma discussão em torno de uma concepção que afirme a centralidade de determinados sujeitos como preferenciais no atendimento dos projetos sociais. Tais sujeitos, localizados por projetos (identificados pelos bairros onde estão sediados e, por consequência, onde vivem seus usuários), também são nominados: "o Carlos, do Mundo", o "Alessandro, do Amigo", a "Juliana, do Kephas". Estes e muitos outros, que por uma questão circunstancial, porém individual, são os que precisam ser "discutidos" e, portanto, ocupam a ata da reunião. São tantos os sujeitos dos quais se precisa falar que uma das educadoras presentes na reunião expressa: "cruzes, é uma turma inteira". 
O fato desses jovens, também nomeados como "arruaceiros", "debochados", frequentarem um projeto socioeducativo, por si, confere um estatuto individual para um problema que é social. Portanto, a exclusão é descontextualizada da dimensão política presente nesse processo. Esta, em geral, arrasta e/ou é arrastada por uma dimensão coletiva; isto é, crianças e, principalmente, jovens de uma determinada comunidade geográfica são sujeitos excluídos porque vivem em zonas urbanas degradadas, não possuem trabalho "fixo" e estão evadidos das escolas. São essas algumas das situações que determinam, segundo os educadores, a necessidade daqueles serem atendidos em projetos sociais. Há em si, também, nessa posição, uma ideia de que esses sujeitos pertencem a "famílias desestruturadas", sem condições de se manter economicamente, de educar e imprimir valores positivos aos filhos. Subjaz, também, a premissa de um grupo/classe que se "contamina" mutuamente e, assim, crianças e jovens das classes populares, filhos de desempregados e subempregados, passam a ser vistos como sujeitos perigosos, o que pode ser constatado no comentário que segue:

O Carlos Ricardo, aquele da mãe que não veio. Ele tem sérios problemas de saúde e ela [a mãe] ainda fica passando a mão por cima e acaba estragando o resto do guri. A gurizada falou que ele briga sempre no colégio. Daí eu chamei e ele não sei o que (...). Que ele briga todo o dia ou chama alguém para brigar. Ele é problemático e precisa de ajuda. Ele fora do projeto a situação vai piorar. (educadora)

Essa fala reitera os projetos sociais como um "ente inclusivo", um lugar onde os jovens devem estar inseridos, incluídos. Não se questiona, nesse episódio e em nenhum outro, o porquê de uma sociedade vulnerabilizar parte de seus jovens.

Por sua vez, a segunda pesquisa analisada, Saberes sobre Diferenças e Inclusão Social $^{8}$, investigou os saberes relativos às diferenças e à inclusão social e como estes vêm sendo construídos entre professores da rede pública e por educadores que atuam em projetos socioeducativos. Foram entrevistados e/ou aplicados questionários semiestruturados a 60 (sessenta) informantes, sendo 15 (quinze) deles educadores que atuam em espaços de educação não escolar, em diferentes cidades do Vale do Sinos/RS, representando um universo de 10 (dez) projetos sociais. Todos, indistintamente, são acadêmicos de cursos de Licenciaturas de uma IES da mesma região. Dos dados referentes a essa pesquisa, no recorte para os 15 (quinze) sujeitos educadores que atuam em projetos socioeducativos, interessa-nos não só a aproximação aos discursos que circulam nos espaços educativos não escolares. Além de nos perguntarmos pelo modo como vêm sendo historicamente constituídos os sentidos sobre identidades e diferenças e seus efeitos na prática socioeducativa, também perguntamos como é tratada a questão da inclusão de sujeitos em desvantagem social.
8. Essa pesquisa, de caráter interinstitucional, foi realizada por pesquisadoras de 3 (três) IES, públicas e privadas, do Estado do Rio Grande do Sul. 
De forma quase unânime, entre os pesquisados, a diferença entre as crianças e jovens atendidos nos projetos não se expressa por uma grande marca, a exemplo da escola, onde os portadores de necessidades especiais (PPDs), em sua grande maioria, são reconhecidos como sujeitos de inclusão. Da mesma forma, não são as dificuldades em relação às aprendizagens e às habilidades - onde a inclusão remete a presença e permanência no ambiente escolar - a questão central no processo inclusivo. No entanto, são também marcas (outras) o que define a diferença e a identidade de sujeitos "em risco social" e, por isso, afetos a projetos socioeducativos. Trata-se de crianças e adolescentes que possuem carências: "não só as familiares, não só materiais, mas afetivas e psicológicas", diz uma educadora. Outros educadores referem: "São aqueles que não tiveram ou tem menos oportunidade de ser alguém na vida, seja por pobreza ou por deficiência"; "São aquelas pessoas que estão de certa forma esquecidas. Cidadãos que tiveram seus direitos tirados. (...) Não estarão recebendo favor, apenas o que é de direito de cada cidadão".

Uma educadora diz que os "sujeitos da inclusão são as pessoas que muitas vezes estão sendo massacradas por algum tipo de vício, que estão em contato com a violência". Na sequência, refere que as pessoas têm sido submetidas a situações de exclusão por motivos diversos, entre eles "a desinformação ou a deseducação proposta pelo sistema politiqueiro adotado no nosso país desde os idos da ditadura que leva [os sujeitos] ao estado de miserabilidade".

Observa-se que, em ambas as pesquisas, o olhar sobre o sujeito da inclusão não é o mesmo. Num primeiro momento, temos um sujeito perigoso e, em outro, um sujeito de falta, que passa a ser visto como vítima da situação da qual faz parte. Tanto numa percepção quanto noutra está presente certa necessidade de (re)colocar esse indivíduo numa ordem; quer no sentido de redimi-lo da culpa ou de repará-lo da falta.

\section{Deslocamentos de sentidos: um processo natural?}

As análises apresentadas até então destacam a ideia de um sujeito que deve submeter-se a uma norma, entendida aqui como um pressuposto necessário para pensarmos a exclusão/inclusão.

Para Veiga-Neto (2001), esse deslocamento dos sentidos atribuídos às identidades dos ditos anormais, que desliza do corpo para o grupo social, tem sido uma constante nos tempos atuais. O argumento, segundo o autor,

(...) se desloca de um plano cuja ênfase incidia sobre a morfologia e a conduta (dos corpos), para um plano cuja ênfase agora se dá sobre a economia e a privação (de determinados extratos sociais) [o que] amplia 
o conceito e o uso da norma como estratégia de dominação. (Veiga-Neto, 2001: 107)

Esse deslocamento nos mostra, ao mesmo tempo, a passagem de uma sociedade disciplinar para uma sociedade de controle. A partir desse deslocamento, Foucault (2007) cunha o conceito de biopoder, em que o controle da vida (enquanto espécie, grupo) será mais relevante que o controle sobre o indivíduo. Dentro dessa perspectiva, os grupos sociais assumem o caráter de "populações", em que a biopolitica se ocupará de gerir a saúde, a alimentação, a segurança e todos os campos que se colocam como desafios políticos. Isso nos permite localizar e falar de uma "população de excluídos", instaurando a noção de cuidado (com a vida) dessa população. Apesar de compartilharmos dessa visão, sentimos a necessidade de enfrentar de forma mais direta essa discussão. Ou seja, é preciso problematizar a desigualdade social, no sentido de identificar de que forma os conceitos de exclusão social vão sendo construídos no atual contexto, em detrimento de uma leitura sobre a desigualdade. Nos perguntamos, então, que implicações estão presentes na mudança de perspectiva da desigualdade para a exclusão? É o que podemos perceber em relação à situação de pobreza, tida pelos informantes como eminentemente excludente, fazendo com que a maioria deles defina as crianças e jovens, com os quais trabalham como sujeitos excluídos e o projeto que os acolhe como um ente eminentemente inclusivo.

Em geral, não há, nos relatos dos educadores, referência às crianças e jovens como sujeitos de inclusão, como, por exemplo, os PPDs nas políticas de inclusão escolar. Para eles, os sujeitos dos projetos socioeducativos são indivíduos excluídos que, em função de suas necessidades básicas não satisfeitas, demandam por equipamentos sociais (e seus projetos) para que tenham compensadas as suas faltas ou corrigidas suas falhas. Assim, os projetos sociais, quando colocados a serviço dos menos favorecidos, têm ressaltados seus atributos de ações inclusivas, demonstrando o quanto os conceitos de exclusão e sua relação com a desigualdade são ainda pouco debatidos.

Esse equívoco reforça a tese do "risco social", o que merece melhor detalhamento. Segundo Fonseca (1997),

As crianças e adolescentes que embora não mantenham a rua como espaço essencial de socialização (o que as faria crianças e adolescentes de/na rua), mantém a característica do risco, em função da miséria, estão no limite: próximos da repetência, da evasão, da expulsão escolar, da violência doméstica, do uso de drogas, da exploração pelo trabalho, da prostituição, das DSTs e AIDS, do abandono (...) cumprindo uma função inversa ao paradigma da infância e da adolescência. (Fonseca, 1997: 84) 
Mesmo que teoricamente superado do ponto de vista teórico, o discurso sobre o risco social e pessoal mantém destaque, especialmente, quando utilizado para referir-se a crianças e jovens das classes populares. Nessa linha de pensamento, ainda reiterada academicamente, e diante da complexidade da situação da juventude, Souza (1999) enfatiza a vulnerabilidade desse grupo social:

A juventude brasileira vive uma vulnerabilidade, apesar de ser um grupo significativo tanto demográfico, quanto economicamente. Podemos tratar sua condição como vulnerável, a partir da compreensão de que existem segmentos sociais que vivem excluídos, com pouca proteção social e sob o fenômeno da vulnerabilidade que nas sociedades latino-americanas varia conforme cada dinâmica social, econômica e moral. (Souza, 1999: 52)

São as situações vulnerabilizadoras, associadas às afirmativas estereotipadas geradoras de preconceito, que vêm contribuindo na manutenção de um imaginário sobre a infância e a juventude como problema social. No entanto, a pecha de excluídos não contribui para a compreensão efetiva das abrangentes questões que envolvem estas fases da vida, especialmente nesse momento em que se torna evidente o prolongamento da convivência com o grupo familiar de origem e da crescente dependência familiar dos jovens. Os estereótipos acerca do universo juvenil geram dificuldades para os próprios jovens, que perdem sua potência de sujeito, e criam dificuldades para aqueles que se ocupam do trabaIho educativo dessa faixa etária.

Ainda sobre a situação que vulnerabiliza os jovens, Souza identifica como sendo uma situação de duplo sentido: de um lado, a vulnerabilidade que envolve os jovens entre si, pelas características típicas da fase que vivem e, de outro, a relação dos jovens com uma sociedade desigual, discriminatória e excludente. Para a autora, "(...) a vulnerabilidade juvenil é forjada tanto na estrutura social quanto nos valores éticos políticos produzidos em suas instituições" (Souza, 1999: 73). Na sua percepção, estas situações concretas denotam dois paradoxos vividos pela juventude: o primeiro, por ser uma parte ativa da economia e estar numa posição de exclusão do mercado de trabalho e das preocupações educacionais; o segundo, pela prescindibilidade da força juvenil nas prioridades das políticas públicas e o discurso da importância da juventude, tornando invisíveis os direitos dos jovens no Brasil.

Destaca-se, na posição da autora, a desigualdade, a discriminação e a exclusão como componentes importantes na análise da vulnerabilidade juvenil. Isso representa um avanço em relação às leituras que vêm sendo feitas sobre essa temática. No entanto, ainda é preciso compreender melhor os mecanismos que propiciam a naturalização do deslocamento da desigualdade para a exclusão. Entre eles, destacamos as legislações.

As legislações afirmativas e seu impacto na produção de discursos sobre 
a exclusão/inclusão social.

Considerando-se a influência dos discursos predominantes na produção de sentidos sobre as diferenças e a inclusão social de crianças e jovens, buscamos, a partir dos estudos de Zucchetti et al (2007), identificar de que forma algumas legislações afirmativas ${ }^{9}$ sugerem, ou não, problematizações sobre o fazer de educadores. Compreendemos que as legislações, como campo de conhecimento e produção de sentidos, incidem sobre a prática educativa e sobre as dinâmicas de instituições onde essas intervenções acontecem. Portanto, afinamos com as autoras na ideia de que as legislações

(...) compartilham uma racionalidade que se destina à parcelas específicas da população, principalmente àquelas que são consideradas vulneráveis aos riscos sociais de discriminação, de marginalização, de pobreza e, conseqüentemente, de exclusão social. (Zucchetti et al, 2007: 75)

Decorrente desse raciocínio, as autoras concluem que a concepção de que

(...) 'todos somos iguais' acaba por referir-se apenas a alguns, sendo que 'outros' necessitam ter suas identidades e diferenças marcadas, (re)nomeadas, para que possam ser inseridas no contexto dos direitos. (Ibidem: 85 )

Dessa forma, a cidadania pretendida pela Constituição Federal de 1988, do ponto de vista pragmático, passa a demandar por legislações que deem visibilidade a sujeitos tidos como diferentes. Nesse sentido, a pretensa cidadania vai depender, num primeiro momento, da diferenciação entre aqueles que são cidadãos (incluídos) e os que necessitam de política de proteção/reconhecimento de direitos para virem a ser cidadãos.

Não basta a condição de vivermos num mesmo território, sob a égide de uma mesma Constituição, falarmos uma língua universal (apesar de seus inúmeros dialetos) para que, como povo de uma mesma nacionalidade, sejamos considerados cidadãos de uma nação. A ideia de consumidores falhos (Bauman, 1998), de cidadãos de segunda categoria (Neto, 2007), conota a cidadania como algo que precisa ser conquistado. Canclini (2001), também salienta que a noção de cidadania foi sendo paulatinamente substituída pela noção de consumidor. Isso nos obriga a revisarmos o próprio sentido de cidadania. Portanto,
9. Entre as legislações afirmativas, o estudo destaca o Estatuto da Criança e do Adolescente (1990), as Diretrizes Nacionais para a Educação Especial na Educação Básica (2001) e as Diretrizes Curriculares Nacionais para a Educação das relações Étnico-Raciais e para o Ensino de História e Cultura Afro-Brasileira e Africana (2003). 
Repensar a cidadania como 'estratégia política' serve para abranger as práticas emergentes não consagradas pela ordem Jurídica, o papel das subjetividades na renovação da sociedade e, ao mesmo tempo, para entender o lugar relativo destas práticas dentro da ordem democrática e procurar novas formas de legitimidade estruturadas de maneira duradoura em outro tipo de Estado. Implica tanto em reivindicar os direitos de aceder e pertencer ao sistema sociopolítico como no direito de participar na reelaboração do sistema, definindo aquilo de que queremos fazer parte (Canclini, 2001: 47).

É nesse sentido que Habermas (2007) tem na cidadania uma das questões centrais quando discute a inserção social, como inclusão ou confinamento. Para o autor, está na relação entre nação, estado de direito e democracia a possibilidade da construção das bases para a cidadania. Assim, a noção de povo, inspirada no romantismo, ao reafirmar a sua existência e sua particularidade na luta contra outras nações, desde a primordialidade natural da imaginária comunidade de língua e ascendência, difunde a ideia de comunidade de destino. Segundo Habermas (2007), essa concepção carrega uma identidade nacional, centrada numa visão etno-nacionalista da soberania popular. Desde essa perspectiva, o autor sugere a identidade nacional como sendo um estreitamento, um fechamento e, por outro lado, a cidadania como uma inserção ampliada que transpõe a visão etno-nacionalista.

Essas reflexões teóricas são fundamentais para que possamos pensar sobre como os educadores se vêm frente aos direitos da cidadania impetrados pelas legislações que eles, em sua maioria, desconhecem. Ao retomarmos os dados do empírico, percebemos que são os projetos nos quais atuam ou que são executados nas suas instituições o principal foco do olhar dos educadores. Aqui, o projeto significa a ação prática realizada com crianças e jovens em risco social e pessoal e não os fundamentos da realidade social que vivem esses sujeitos, muito menos as políticas de governo como sendo premissas importantes na sustentação de suas proposições.

10. Maiores informações sobre estes programas podem ser acessados no sitio do Ministério do Desenvolvimento Social.
Nesse sentido, o Programa de Erradicação do Trabalho Infantil (PETI), o Pró Jovem, o Agente Jovem, o Bolsa Família ${ }^{10}$, ao serem citados pelos educadores, são referenciados pela sua concretude, pela ação prática, destituído de qualquer reflexão: "Os sujeitos devem ser incluídos pelo simples fato de [que] todos somos iguais perante a lei" (educador).

Por outro lado, legislações como o Estatuto da Criança e do Adolescente (1990) e a Lei Orgânica da Assistência Social (1993) são criticadas por excesso de idealização, tal como expressado por uma das educadoras: "Li um pouco de cada uma das legislações. A maioria delas é apenas um sonho ou mais uma lei 
que está lindamente escrita (...) muitas vezes por pessoas que não conhecem quase nada da realidade dos excluídos (...)".

Essa ambiguidade demonstra que a concretude identificada nos programas vai de encontro à idealização atribuída às leis, o que reflete a falta de preocupação delas para com a sustentação legal dos próprios programas sociais, garantindo a continuidade das ações.

Assim, quando objetiva e forçosamente fazem referência às legislações com as quais tiveram um contato mais imediato, os educadores mencionam especialmente o Estatuto da Criança e do Adolescente (ECA). Nele, ressaltam o direito de crianças e adolescentes de serem assistidos no contra turno da escola; destacam, também, as atividades de apoio escolar, alimentação, higiene, etc. É interessante observar que, embora o ECA, no seu artigo 90, faça referência aos programas de proteção e, entre eles, os projetos socioeducativos apareçam como direito de todos - dado o caráter universal e universalizante do mesmo - é a noção de sujeito da falta e/ou perigoso que determina, para os educadores, a prioridade de ingresso de crianças e jovens brasileiros nos programas sociais pesquisados. Desta forma, enquanto o ECA propõe o direito à infância na sua integralidade, os educadores recortam o Estatuto e se apegam à dimensão compensatória e normatizadora.

Desde esses pressupostos, é possível verificar, de forma geral, que o ECA não aparece como um interlocutor entre o projeto socioeducativo e a prática do educador e, sim, como um instrumento jurídico que define os direitos dos usuários desses "serviços"11.

Quanto à interferência das legislações afirmativas e o seu cumprimento por parte dos gestores públicos, verifica-se que, para os educadores dos projetos socioeducativos, essa questão fica relativizada ou, no mínimo, não é considerada como sendo afeta a eles. No âmago disso está a ideia de que projetos de caráter social, dado o seu enfoque compensatório e/ou normatizador, são inclusivos por excelência ${ }^{12}$, por isso os educadores não se preocupam com as legislações. Isto é, basta uma criança e/ou jovem (sujeitos preferenciais nas práticas onde atuam os educadores pesquisados) comprovar a sua condição socioeconômica e sua "vulnerabilidade/risco social" para que adquira as credenciais necessárias para fazer parte de algum projeto social. Nesses casos, considera-se apenas a faixa etária dos sujeitos, a frequência escolar, entre outros fatores.

\section{Algumas considerações finais}

Neste artigo, ao trabalharmos com a hipótese da naturalização do fenômeno exclusão/inclusão nos projetos socioeducativos, queremos destacar o quanto o tema é pouco problematizado pelos educadores. A naturalização de que todo
11. A dimensão de um serviço que é prestado a alguém está registrada nos portais do Governo Federal quando define que o socioeducativo é destinado a um público especifico, referindo-se ao Programa de Erradicação do Trabalho Infantil (PETI) e o Programa Nacional de Inclusão de Jovens (Prólovem). Ver sítio do Ministério do Desenvolvimento Social (MDS).

12. Dados da pesquisa demonstram que, no recorte para os professores das escolas, a inclusão escolar é realizada considerandose, especialmente, a legislação em vigor. Os professores das escolas que participaram da pesquisa deixaram transparecer um certo esgotamento quanto à prática da docência inclusiva. Sentemse compelidos pelas legislações e pelas instituições escolares a dar conta dos "sujeitos incluídos", mas reforçam a quase inexistência de condições materiais e humanas para realizar tais intervenções. Identifica-se que esta é uma das grandes divergências verificadas pela pesquisa, entre os educadores e os professores das escolas públicas, para a questão da inclusão e das diferenças. 
o projeto socioeducativo é inclusivo, permeado pela concepção de que as crianças e jovens atendidos são sujeitos excluídos, subtrai dessa discussão a dimensão da desigualdade que define a priori aqueles que deverão ser alvo de políticas compensatórias.

Segundo Santos (2008), trata-se de um "dispositivo ideológico de gestão da desigualdade e da exclusão" (p. 283). A ideia de que todos são excluídos, em realidade, nega as diferenças e homogeniza as características de sujeitos desiguais. Trata-se de uma face de um mesmo processo de gerenciamento da desigualdade que, contraditoriamente, também absolutiza as diferenças.

Para Santos (2008), o sistema de gerenciamento da desigualdade e da exclusão visa manter a própria desigualdade sob parâmetros de controle e tolerância sociais, garantindo o que ele chama de "integração subordinada", operada por meio das políticas estatais. É desse modo que projetos socioeducativos também gerenciam a desigualdade e a exclusão. Enquanto políticas compensatórias, ao serem oferecidas como condição de acesso a estágios iniciais de cidadania, também servem para, de certo modo, neutralizar e padronizar as formas de ser jovem e de ser criança, capturando toda a potência da diversidade cultural e de diferentes formas de expressão da infância e da juventude.

Assim, fica claro que a preocupação com a inclusão, da forma como vem sendo feita, não incide sobre as questões de fundo. Para tanto, torna-se fundamental considerar que qualquer discussão sobre inclusão social impõe, necessariamente, repensar o próprio sistema socioeconômico e político que produz a exclusão.

Nesse sentido, é impossível desconsiderar o impacto da formação acadêmica para educadores que atuam em práticas de educação não escolar e que estão realizando cursos na área da formação de professores em nível superior. Ainda mais quando os próprios educadores afirmam ser a formação acadêmica um dos limitadores de uma intervenção contextualizada, crítica, onde a dita prática inclusiva nesses espaços prescinde de problematização, de metodologias, de recursos próprios. Isso porque se, por vezes, a discussão sobre a exclusão/ inclusão, desigualdade/integração subordinada é exígua, noutras a formação acadêmica prioriza o debate em torno da inclusão de portadores de necessidades especiais nas escolas.

Certos de que ainda temos muito a avançar acreditamos que este texto possa trazer contribuições para aprofundar uma temática que tem sido recorrente no campo da educação, ou seja, a exclusão/inclusão.

Abstract: This article discusses the topic of exclusion/inclusion in practices of non-academic education, based on the speeches of educators who work in socio-educational projects for children and youngsters in the outskirts of urban 
centers. Considering some results of the empirical research projects Formação de Educadores em Práticas Socioeducativas (Training of Educators in Socioeducational Practices - CNPq) and Saberes sobre Diferenças e Inclusão Social (Knowledge on Differences of Social Inclusion), socio-educational projects are regarded as essentially inclusive actions, naturalizing the phenomenon of social exclusion/inclusion. We propose the expansion of this discussion supported by arguments that suggest the lack of an important foundation, namely the dimension of inequality.

Keywords: publics policies; exclusion/inclusion; inequality; socio-educational projects; educational practices.

\section{Referências}

Bardin, L. (1991) Análise de Conteúdo. Lisboa: Edições 70.

BAUMAN, Z. (1998) O mal estar da pós modernidade. São Paulo: Zahar.

BRASIL (1995) Lei no 8.742 de 7 de dezembro de 1993. Dispõe sobre a organização da Assistência Social e dá outras providências. Brasília.

. Lei Federal no 8.069 de 13 de julho de 1990. Estabelece o Estatuto da Criança e do Adolescente. Disponível em: http://www.planalto.gov.br/ccivil/ LEIS/L8069.htm, Acesso em: 12/08/2009.

. Resolução $n^{\circ} 2$ de 11 de setembro de 2001. Institui as Diretrizes Nacionais para a Educação Especial na Educação Básica. Disponível em: http://www. planalto.gov.br/ccivil/LEIS/L8069.htm, Acessoem:12/08/2009.

. Resolução no 2 de 11 de setembro de 2001. Institui as Diretrizes Nacionais para a Educação Especial na Educação Básica. Disponível em: http://www. planalto.gov.br/ccivil/LEIS/L8069.htm, Acesso em: 12/08/2009.

. (2003) Lei Federal no 10.639 de janeiro de 2003. Estabelece as Diretrizes e Bases da Educação Nacional, para Incluir no Currículo Ocial da Rede de Ensino a Obrigatoriedade da Temática 'História e Cultura Afro-Brasileira'. Brasília.

. (1995) Lei no 8.742 de 7 de dezembro de 1993. Dispõe sobre a organização da Assistência Social e dá outras providências. Brasília.

Carvalho M. do C. \& Azevedo, M. J. (2004) Ações complementares à escola no âmbito das políticas públicas. Inédito.

Canclinı, N. G. (2001) Consumidores e Cidadãos: conflitos multiculturais da 
globalização. 4a. ed. Rio de Janeiro: Editora UFRJ.

FonseCA, L. (1997) Plano global do CIP. Inédito, 86 p.

Foucault, M. (2007) Nacimiento de la biopolítica. Buenos Aires: Fondo de Cultura Econômica.

Franco, M. L. (2008) Análise do Conteúdo. Brasília - DF: Liberlivro.

Habermas, J. (2007) A Inclusão do Outro. Estudos da teoria política. São Paulo: Loyola.

Haddad, S. (2009) "Homenagem". in Revista Brasileira de Educação, Vol. 4, n. 41.

Neto, A. M. Entrevista. Acesso em: 23/12/2007. Disponível em: http://www. ipea.gov.br/003/.

MouRA, E. P. \& ZucChETTI D. T. (2007) “Educação não escolar: reetindo sobre práticas para uma (outra) epistemologia". In Contrapontos (Univali), Vol. 7, n. 1: 165-177.

MouRA, E. P. (2009) "Educação não escolar, universidades e educação popular: horizontes de novos desaos". In Educação Unisinos, Vol 13, n. 2: 125-134.

SAntos, B. S. (2008) A Gramática do Tempo: para uma nova cultura política. São Paulo: Cortez.

SouzA, J. T. (1999) "Os jovens, as políticas sociais e formação educativa". In Revista de ciências humanas, Vol. 26: 51-79.

Veiga-Neto, A. (2001) "Incluir para excluir". In Larrosa, J. \& Skliar, C. (ed.) Habitantes de Babel: políticas e poéticas da diferença. Belo Horizonte: Autêntica: 105-118.

Zucchetti, D. T. \& MourA, E. (2007) "Educação não escolar e universidade: necessárias interlocuções para novas questões". In 30 Reunião Anual da Anped. Araxá: 14.

Zucchetti, D. T.; Klein, M. \& Sabat, R. (2007) "Marcas das diferenças nas políticas de inclusão social". in Revista Educação e Realidade, Vol. 32, n. 1: 75-90. 